\title{
USING SYSTEM DYNAMICS TO MODEL THE SOCIAL CARE SYSTEM: SIMULATION MODELING AS THE CATALYST IN LINKING DEMOGRAPHY TO CARE DELIVERY
}

\author{
Sally C. Brailsford \\ Maria Evandrou \\ Rebekah Luff \\ Richard Shaw \\ Joe Viana \\ Athina Vlachantoni \\ Rosalind M. Willis \\ University of Southampton \\ Southampton SO17 1BJ, UK
}

\begin{abstract}
This paper describes a system dynamics model for social care, developed in collaboration with a local authority in England, as part of the UK Engineering and Physical Sciences Research Council Care Life Cycle project based at the University of Southampton. The model was populated with data from a wide range of sources, local and national. We present some illustrative results, and discuss the process of model development and the challenges around data collection. We also discuss the benefits derived from codeveloping such a model with practitioner users and as part of a multi-disciplinary team involving demographers and social statisticians.
\end{abstract}

\section{INTRODUCTION}

The last century witnessed a transformation of the UK population. In 1901 the population of the UK was 39.3 million; by 2011 it had grown to over 62 million. This growth in the absolute size of the population has been accompanied by changes in its composition, the most marked of which has been a rise in its average age. In 1901, people aged 65 and over comprised around 5\% of the total population, by 1941 this had doubled to $10 \%$ and by 1981 the percentage reached 15\% (HC 1999). Today, 16\% of Britain's population is aged 65 and over, and the proportion has been fairly stable for the last 20 years. However, over the next 30 years there will be a significant rise in the share of the older population as the baby boom cohorts (those born immediately following the Second World War and in the late 50s to mid-1960s) begin to enter retirement. In $202120 \%$ of the population will be aged 65 and this will rise to $23 \%$ by 2031 and $25 \%$ by 2041 (ONS 2011a).

At the same time, the older population itself is aging. Improvements in mortality rates mean that more of the large baby boom cohorts are surviving longer. Current projections suggest that that more than 95,000 of those people aged 65 in 2012 (born in 1947) are expected to celebrate their 100th birthday in 2047 (ONS 2012). Although people are living longer, not all of those years are spent in good health. In Britain, between 1981 and 2007 the number of years during which people aged 65 and over might experience limiting illness or disability rose from 5.4 to 7.1 years for men and from 8.4 to 8.9 years for women (Office for National Statistics 2004, 2011b).

The rise in the number of older people who may be unable to complete the tasks required for every day living will put increasing pressure on the health and social care system. At the same time, demo- 


\section{Brailsford, Evandrou, Luff, Viana, Vlachantoni and Willis}

graphic and socio-economic changes such as changing family structures, increasing female employment and lower fertility mean that the ability of the informal (family) sector to meet this increased demand may be limited, whilst the health and social care workforce itself will be aging. The EPSRC Care Life Cycle (CLC) project aims to develop a suite of models that address both supply and demand for health and social care (both formal and informal), explicitly recognizing the fact that these systems interact in complex ways and feedback on each other. The CLC team brings together researchers from across a range of disciplines including operational research, gerontology, social policy and complexity science.

The model detailed in this paper examines the social care sector from the perspective of the local authority provider, highlighting how changes in both demand for services and supply in other parts of the systems (from the family and the health care system) will impact on the required levels of local authority provision. Section 2 provides more detail on social care in the UK. Section 3 then briefly reviews previous applications of simulation in social care, whilst details of the model itself are presented in section 4 along with the sources of data in section 5. Model results are presented in Section 6 and the paper concludes with reflections on the benefits of interdisciplinary working in section 7 .

\section{SOCIAL CARE IN ENGLAND}

Social care can be defined as assistance received by people who are disabled, sick or vulnerable, in order to enable them to function in their everyday lives. Examples of the types of assistance involved range from help with bathing or feeding for the most severely impaired, to social interaction facilitated through day centers for people with learning disabilities or older people (Hill 2000). Social care takes place in a variety of settings, including assistance in a person's own home, activities in community centers, and placements in residential care homes.

Social care services in England are usually divided into two main types: child services and adult services (Hill 2000). In this paper we are interested in adult services, and more specifically those provided to people over the age of 65 . However, we acknowledge that the "new aging populations", i.e. the growing population of people who are surviving conditions that were traditionally thought of as diseases of childhood such as Cystic Fibrosis, are entering adulthood and mid-life with complex care needs (Iles and Lowton 2008).

There is a division between social care and health care in England. Health care is provided by the National Health Service (NHS), is funded through general taxation and is free to all patients at the point of need. Social care, on the other hand, is not universally free to all who have a need. Furthermore, responsibility for providing and financing social care is devolved to the local level to county or city councils, called 'local authorities', and there is no national care service comparable to the NHS.

The funding of social care in England is often referred to as a 'mixed economy' (Glasby 2012). This term refers to the different sources of social care: informal care provided unpaid by family members or friends; and formal care provided by the state, the private sector or the voluntary sector. To make the picture even more complex, many people receive care from more than one source; and care can be provided by private services but paid for through state funding. The vast majority of social care is provided by informal sources. It is estimated that local authority funded care accounts for $25 \%$ of the total social care provided to older people; the bulk is provided on an unpaid basis by informal carers, and the rest is purchased privately (Sillett, Cookson and Elliott 2008).

Free state social care is rationed. Only those people who are assessed as having a high level of need, and who have a low level of financial resources are eligible for free state social care. The criteria by which these assessments are made can vary across local authorities. People who do not meet these criteria, e.g. if they have moderate or low needs, have to rely on informal care, pay for care from private sources, or do without (Sillett, Cookson and Elliott 2008).

In order to effectively plan and provide future social care services, local authorities need to balance increasing restrictions on financial resources and the changing needs of their local population resulting 
from demographic and social forces. This paper presents a system dynamics model to help local authorities in this complex planning task.

\section{MODELING SOCIAL CARE SYSTEMS}

In the operations research literature there have been very few applications of simulation in social care, compared with the vast number of applications in health care over the past sixty years (Brailsford et al, 2009). Moreover, even within health care the overwhelming majority of these models have used discreteevent simulation (DES), and it is only within recent years that system dynamics (SD) has gained wider acceptance in the mainstream health OR community (Brailsford 2008). One notable exception is Wolstenholme (1993), the highly cited SD study of the UK social care system. Wolstenholme's model was designed to illustrate some of the undesirable unintended consequences of the UK government's "Care in the Community" initiative, whose laudable aim was to include people with mental and/or physical disabilities within "mainstream" society by moving them out of long-term institutional care and into sheltered housing in the community. This model was mainly qualitative and was only ever implemented with illustrative data as a management training game.

One of the earliest examples of quantitative simulation modelling in social services is by Campbell et al. (2001), who used DES to compare the costs of a "Hospital-at-Home" service with conventional residential care. Later, Katsaliaki et al. (2005) developed a DES model to study the impact of a proposed policy to reduce "bed-blocking" in acute hospitals by imposing a financial penalty on a local authority if an older patient was medically fit for discharge but was prevented from leaving hospital by the lack of a residential care place. Following this, Desai et al (2008) developed an SD model to investigate future demand from older people for social care services in Hampshire, UK. The aim of this model was to explore the significant challenges of an aging population, in the context of budget limitations, over the next five years, and to explore the effects of two possible interventions to meet these challenges.

In more recent years, perhaps the best known SD models for social care in the UK have been developed by a consultancy firm, the Whole System Partnership (www.thewholesystem.co.uk). These models have not been published in the academic literature but full details can be found on the WSP website and also as case studies on the MASHnet (2012) website, http://mashnet.info/case-studies/. One of these models was designed to provide a learning opportunity for planners and providers to review and explore different local reablement services (in terms of both capacity and service models). Another model was developed to assist Local Authorities to implement the UK's National Dementia Strategy for their own population. As the name suggests, these models take a "whole systems" view which is one of the key strengths of SD, but are at a fairly high level of aggregation. The model presented in this paper reflects many of these advantages (and disadvantages). Typically, SD models are not designed to yield exact numerical predictions but are intended to allow stakeholders and problem owners to learn about their system and explore policy options by investigating the knock-on effects of different interventions, as perfectly illustrated by Wolstenholme's 1993 model.

\section{THE MODEL}

This model was developed partly in collaboration with an anonymous English local authority (referred to in this paper as Blankshire County Council). However the model is designed to be generic and therefore, as Section 5 explains, much of the data used in the model are UK national data.

The model was developed in Vensim and represents the population aged 65 and above in a typical English county. The model contains a number of "stocks" which represent the different states that people can be in, corresponding, broadly speaking, to their need for social care or support and the means by which this need is met. The overall structure of the model is depicted schematically in Figure 1. 


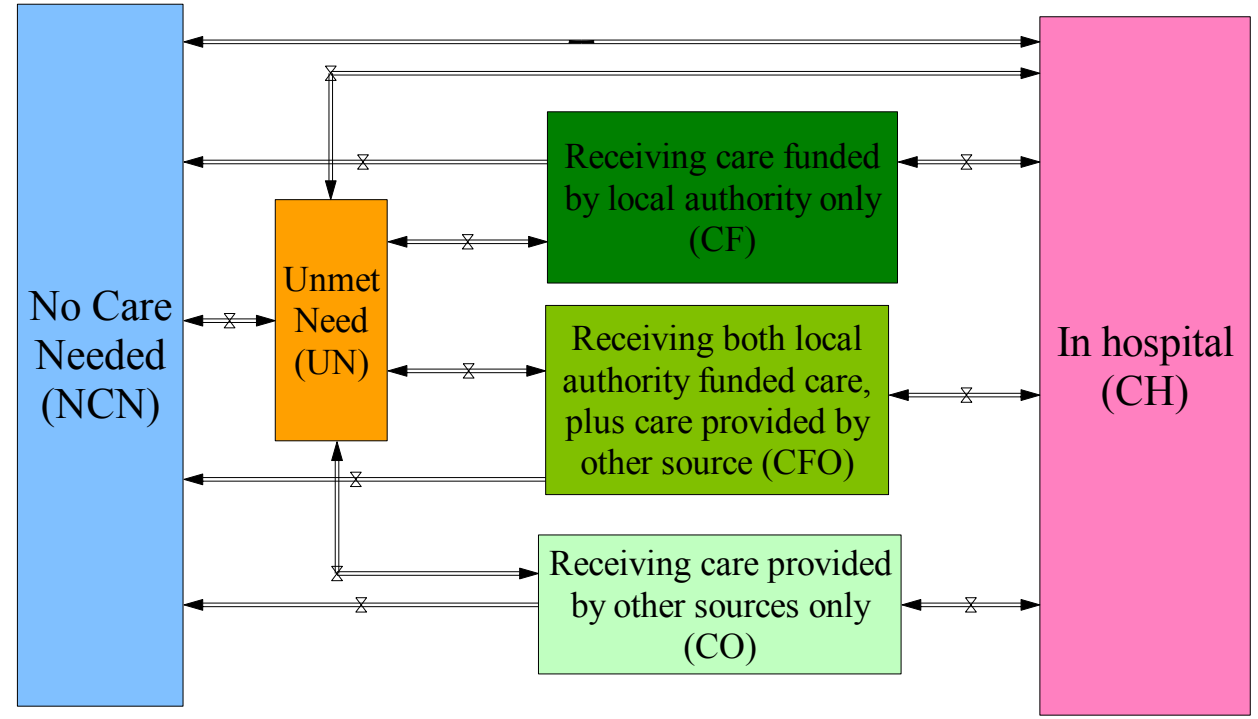

Figure 1: High-level schematic of the model structure

The blue box (stock) on the left represents the population aged over 65 who have no social care need and are able to live independently. Over time, they may develop a care need and move into the orange stock. This care need can be met in three possible ways: either entirely funded by the local authority, or by "other sources", or by a combination of the two, as depicted by the three green boxes in Figure 1. "Other sources" includes both informal care provided by family or neighbors, and formal care from a private, commercial provider and paid for directly (out-of-pocket) by the recipient or his/her family. It is of course possible to move from any of these states back into the "No Care Need" state, for example if a person recovers from some physical illness which had resulted in a temporary care need. From both the green and blue boxes, it is possible to move into (and back from) the pink "Hospital" box on the right hand side, which represents emergency or acute interactions with the NHS. Of course, many people in both the blue and green boxes will be receiving NHS treatment for a chronic illness such as heart disease or diabetes, but this does not necessarily mean that they need social care unless they are unable to carry out certain Activities of Daily Living (ADLs) or Instrumental Activities of Daily Living (IADLs) (Katz et al. 1983). ADLs include basic self-care tasks like being able to toilet, feed or wash oneself, whereas IADLs cover a broader range of activities such as housework, shopping or being able to manage one's finances.

People "arrive" into this model solely by the process of aging: we have not included migration (in or out) in this particular model. The model also contains a less easily quantifiable variable, "willingness and resources", which attempts to capture people's propensity to provide informal care for their elderly relatives. This does not merely reflect their physical and financial ability to do so, but also their personal inclination, and it influences the fraction of people who move into the lower two green boxes. The model also includes death from any of the six states.

The CLC team has developed a far more complex version of this model for Blankshire County Council, in which the six states in Figure 1 are subdivided into separate age bands and the four care-related states are further subdivided into the four categories widely used by all UK local authorities, namely Low, Moderate, Substantial and Critical. However, the data requirements for this version of the model are daunting, as the number of sub-states is combinatorially large. Therefore in this paper we have aggregated all these subgroups and consider only a population average, using data from a variety of national sources as described below. The actual data used in the model are shown in Appendix A. 


\section{DATA SOURCES}

The data utilized within the model presented in this paper have been gathered from a range of nationallyrepresentative datasets covering such topic areas as demographic characteristics (e.g. age, gender); report of general health and limiting long-standing illness, i.e. chronic disease which impacts on a person's ability to perform ADLs or IADLs; report of diagnosed physical or mental health conditions; report of difficulty with ADLs or IADLs; receipt of support/care from different sources (formal state, formal paid for, informal); and episodes of hospital and care home admissions/transfers. In addition, the model has used raw data from a range of sources in order to calculate such indicators as the need for social care, the mortality rate for different age groups, and recovery rates (no longer needing formal state care). Below is a brief description of the data sources used. The actual data are listed in the Appendix.

\subsection{UK National Datasets}

The Office for National Statistics (2006) Subnational Population Projections dataset contains population projections up to 2026 for Local Authorities and Primary Care Organizations in the UK. The Office for National Statistics (2001) Health and Provision of Unpaid Care dataset is derived from the 2001 Census and includes geographical information in relation to the report of limiting long-standing illness, general health and informal care provision. Finally, the Hospital Episode Statistics (HES) dataset (2010/11) records the healthcare provided by NHS hospitals in England and for NHS hospital patients treated in the community.

\subsection{Longitudinal Datasets}

The English Longitudinal Study of Ageing (ELSA 2008) is a study of persons aged 50 and over living in private households in England, and covers a range of domains, such as demographic and socioeconomic characteristics, the report of general health and long-standing illness, physical and mental health conditions, the report of difficulty with mobility functions, ADLs and IADLs, as well as the provision of informal support and the receipt of formal state, formal paid or informal support. The British Household Panel Survey (BHPS 2008) is a longitudinal survey aimed at understanding social and economic change at the individual and household level in the UK. It was designed as an annual survey of adult members (aged 16 and over) of a nationally representative sample of private households. Finally, the General Household Survey (GHS 2001) is a survey of a representative sample of the British population residing in private households, which has run occasional modules relating to older persons and informal care provision. The core topics of the GHS include key demographic (eg. marital status) and socioeconomic (e.g., housing tenure, employment) characteristics, as well as key indicators relating to health status, health-risk behaviours and the use of health services. In 2001-02 the GHS included a special module which focused on people aged over 65 and their health, as well as their ability to perform ADLs and IADLs.

\subsection{Mapping Data to Eligibility for Social Care}

One of the key aspects of this model is the flow of persons in and out of social care, based on the persons' need and eligibility for full, or part-funded formal state care. Although the categories used to distinguish individuals' need across Local Authorities in England are the same (low, moderate, substantial, critical), nevertheless the information used to place individuals in different categories may differ in different Local Authorities. In addition, state formal care is usually provided to individuals who have been deemed to have substantial or critical need for social care, and means-testing may be part of such considerations. The model draws on the assessment material used by Blankshire County Council, as well as discussions between the researchers and Social Workers involved in the assessment process. Within this particular Council, an initial assessment, which may lead to a more detailed assessment of care needs, encompasses such areas as a person's practical aspects of daily living (e.g., IADLs), personal care (e.g., ADLs), meals 
and nutrition, socialization, safety, need for support, and safeguarding, which is an indicator of a person's vulnerability to abuse. Key criteria relating to an individual's reported need for care on the one hand, and available resources or support networks on the other hand, are used in the identification of individuals who are deemed to have substantial or critical need and are therefore eligible for formal state care. Such criteria were 'mapped' onto variables which were available in a range of datasets, however such matching was not always possible. For example, an individual's report of difficulty with at least one ADL is a central indicator of need for care, whereas an individual's risk of physical or other types of abuse is more difficult to operationalize in the model. Similarly, the availability of family networks and the willingness of family members to provide care will affect the receipt of informal support. At the same time, nationallyrepresentative datasets are limited by their lack of inclusion of older persons residing in care homes, and by their poor coverage of more vulnerable groups, including persons suffering from dementia.

\section{MODEL RESULTS}

In this section we present the results of some experiments to explore the impact of the variable "Willingness and Resources", denoted by WR. As briefly mentioned in Section 4, this parameter represents the propensity of families, neighbors and friends to provide informal care, and is difficult to quantify numerically. However, SD allows rapid experimentation with different hypothetical values of such unknown (and possibly unknowable) parameters and enables us to understand not only what their impact could be, but also how they could be influenced. Some qualitative research is under way within the CLC project to investigate the "familial obligation" aspect of the parameter WR, through in-depth interviews. System dynamics is an ideal tool to explore this sort of variable, which is clearly a very important factor in the provision of informal care and may potentially have a major impact on the entire social care system, but is very difficult to estimate accurately. In the model, WR can take values from 0 to 1 , where 0 means that the person's family is completely unwilling or unable to provide any informal care at all, and 1 means that they are willing and able to provide all the care that is needed. Initial findings from the above-mentioned CLC study suggest the current baseline value of WR is around 0.4 , and this value was used in the model validation experiments. Figures 2 and 3 below presents some results where WR was varied, and show the numbers of people in various states in the model. The model was run for 300 months with a time-step of 1 month.

It is interesting, and concerning, to note how the difference between adjacent settings of WR increases closer to zero. Figure 3(a) shows that the level of unmet need in this population remains relatively stable over time, provided WR is equal to 0.4 or more. At $\mathrm{WR}=0.4$, about 22,500 people are in this state over the whole period. However, should WR fall to 0.2, the level of unmet need rises considerably (over 33,000 after 300 months) and should it fall to zero, over 63,000 people are in this state after 300 months.

Figure $3(\mathrm{~b})$ shows that (all other things remaining equal) the burden on the local authority, Blankshire, also increases non-linearly with a decrease in WR. This will clearly be of concern to Blankshire (in times of considerable financial constraint) since all local authorities have a statutory duty to provide care to people who meet their criteria and who have no other means of support. This non-linear increase is echoed in Figure 3(c), depicting the slightly larger number of people whose care needs are met jointly by Blankshire and other sources. In Figure 3(d), we see that as WR gets closer to zero, after 300 months the number of people receiving care from "Other", which includes privately funded care, drops from around 54,500 for $\mathrm{WR}=0.4$ to just under 14,000 for $\mathrm{WR}=0.0$. Removing the contribution of family, neighbors and friends clearly shows the huge care burden currently borne by these people. If they were indeed no longer willing or able to provide care, the impact on the local authority care budget would be dramatic. 


\begin{tabular}{|l|l|l|l|}
\hline 1.0 & & 0.4 & \\
\hline 0.8 & & 0.2 & \\
\hline 0.6 & & 0.0 & \\
\hline
\end{tabular}

Figure 2: Color-coding for the value of WR (Willingness and Resources)

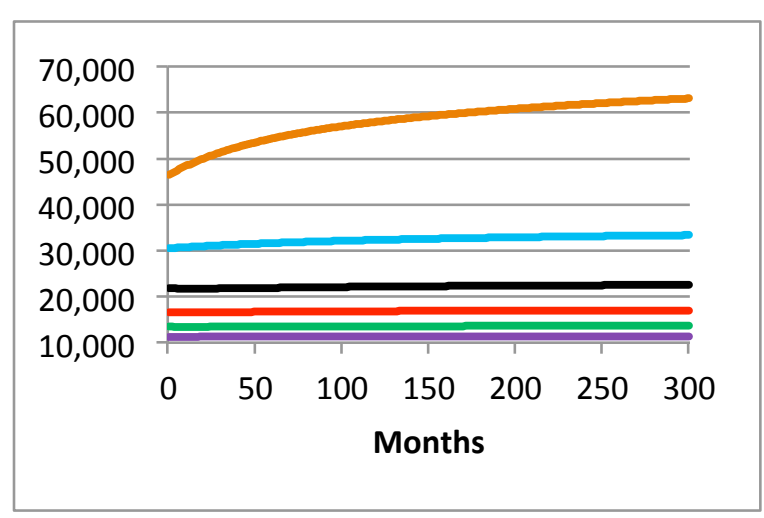

(a): Unmet Need

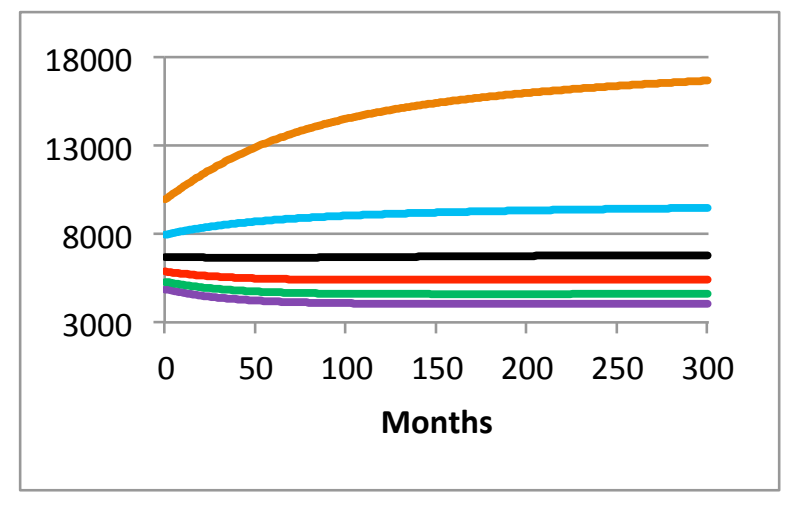

(c): Care met by both

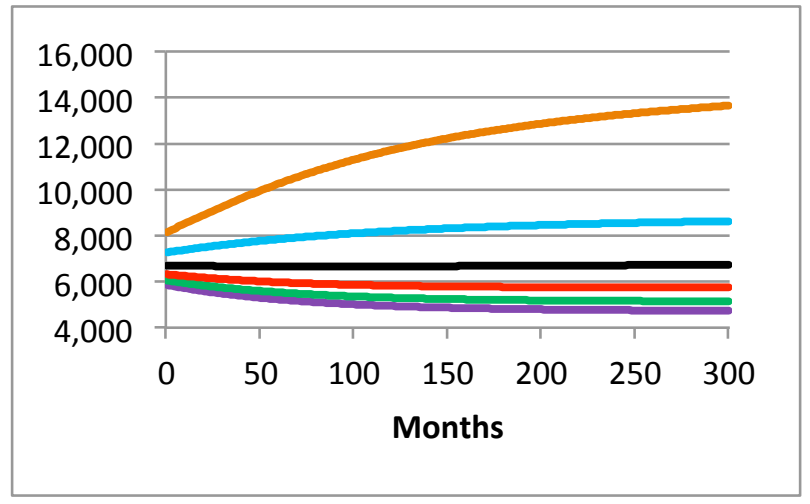

(b) Care funded by Blankshire only

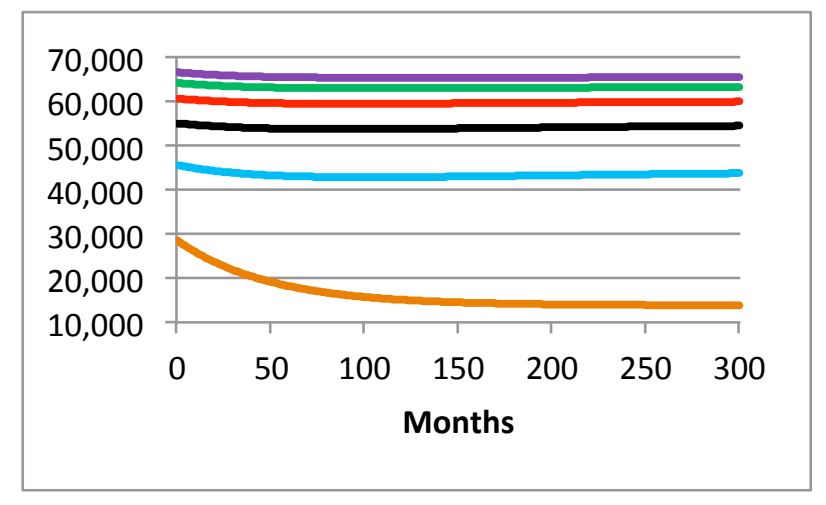

(d) Care funded by Other only

Figure 3: Numbers of people in different care receipt states over time, for different values of the parameter WR (Willingness and Resources)

\section{DISCUSSION}

The experiments presented above explore different values of the hypothetical parameter WR. This is related to a number of factors, some of which are financial or physical, and others are psychological or emotional. For example, an elderly couple where the wife has dementia may be able to cope independently while the husband is fit and well, but if he himself should become disabled or fall ill, then he may be no longer physically capable of providing care for her. An unmarried woman in her 50's may wish to give up paid employment to care for her aging parents, but in doing so she would be impacting not only on her current earnings and standard of living, but also on her future pension and her quality of life in her own old age. Other aspects are less easily measurable in financial terms. In today's society, where people are much more geographically mobile than in the past, children do not always live just round the corner from their parents. Geographical distance is often a major issue for families when elderly parents begin to become infirm and require more frequent support. Moreover, changing family structures due to the increasing divorce rate have resulted in more varied family relationships, and it is far from clear whether people 
feel the same sense of familial duty and obligation to care for (say) their 85-year-old ex-mother-in-law, who may live several hundred miles away and with whom they have had no contact for 20 years, as they do for their own birth parents.

The data in this model were derived from a variety of sources, ranging from national-level datasets through to local Blankshire data and even the expert opinions of individual social workers, and covering different periods of time. For operations researchers, who are accustomed to combining disparate datasets and using whatever data they can obtain, this was not a problem. However the social scientists were understandably more concerned about these issues, and were less comfortable still about using expert opinion. However, the input of the demographers and social statisticians meant that the modelers were made aware of the consequences (say) of using UK-level data for the Blankshire population, even although in the model presented here the data were not adjusted for known demographic differences between these populations. From a purely predictive standpoint, this is of course a limitation of the model.

Of course, this model (like all models) is a simplification of the real system. It does not subdivide people by age or care need category and just takes an average over the whole population over 65 . It does not allow the system to respond to changes, but assumes that everything else remains constant while the parameter WR is varied. Moreover, it assumes that the "arrival rate" remains fixed over time, which is obviously not the case since the population is aging. Nevertheless, the model shows some clear lessons for Blankshire: the model is in fact a best case since increasing numbers of over-65's will only serve to make the problem more severe.

\section{REFLECTIONS}

This model has highlighted many of the benefits, and a few of the challenges, of cross-disciplinary working. The demographers and social statisticians in the CLC were well informed about, and had access to, key sources of data which the modelers did not even know existed. Conversely, the concept of system dynamics modeling was new to the demographers and opened up new possibilities for developing models in their own application domains. However, there were some issues: while the modelers were quite happy to use data from different sources or time periods, this gave rise to some methodological angst among the social statisticians. Similarly, the modelers were much more comfortable about using "educated guesses" to calibrate the model than their social science counterparts, and felt more confident that (despite all these caveats about the data) the model had something useful to say to Blankshire which gave insights into their real-world system. While the social statisticians would have preferred not to expose the model to Blankshire until they were confident in the data underpinning it, the modelers were happy to work with Blankshire and develop the model together, no matter how dubious some of the data were.

Future work on this model will entail addressing many of these limitations (subdividing the population by age band and care need category; incorporating in- and out-migration; obtaining better estimates for the time spent in the Unmet Need state; including time-dependent arrival rates; breaking down some of the overall averages, such as the hospital admission rate, into state-specific parameters) and on working with Blankshire to obtain data from their own systems, rather than fall back on national data.

\section{ACKNOWLEDGMENTS}

We gratefully acknowledge the many helpful discussions with the remaining members of the CLC research team not named explicitly as authors on the paper: Seth Bullock, Amos Channon, Jane Falkingham, Jonathan Klein, Jason Noble, James Raymer, James Robards, Stuart Rossiter and Eric Silverman. We also gratefully acknowledge support from the EPSRC under grant EP/H021698/1. Finally, we would like to express our gratitude to all the staff at Blankshire County Council. 


\section{APPENDIX A}

The following terms are used in this table, corresponding to the six mutually exclusive states in Figure 1:

- $\quad \mathrm{NCN}=$ no care need

- $\mathrm{UN}=$ unmet need, i.e. with a need but receiving no care or support

- $\mathrm{CF}=$ Solely receiving care funded by Blankshire

- $\mathrm{CO}=$ Solely receiving care provided by some other formal or informal source

- $\mathrm{CFO}=$ Receiving care from both the above two

- $\mathrm{CH}=$ Hospital stay

The time step is one month and all rates are per month. The model run length was 300 months. "Workstream A analysis" refers to work undertaken within other parts of the CLC project.

ELSA is the English Longitudinal Study of Ageing (see Section 5.2).

\begin{tabular}{|c|c|c|}
\hline Variable & Value & Source \\
\hline Total initial population aged 65 and over & 250,000 & Based on a typical English county \\
\hline Fraction of the initial population in $\mathrm{NCN}$ & $61 \%$ & Workstream A analysis, ELSA 2004 \\
\hline Fraction of the initial population in UN & $11.6 \%$ & Workstream A analysis, ELSA 2004 \\
\hline Fraction of the initial population in $\mathrm{CF}$ & $2.6 \%$ & Workstream A analysis, ELSA 2004 \\
\hline Fraction of the initial population in $\mathrm{CFO}$ & $2.4 \%$ & Workstream A analysis, ELSA 2004 \\
\hline Fraction of the initial population in $\mathrm{CO}$ & $21.4 \%$ & Workstream A analysis, ELSA 2004 \\
\hline Fraction of the initial population in hospital & $1 \%$ & Wanless Report (2006), p6 \\
\hline Monthly transition rate from $\mathrm{NCN}$ to $\mathrm{UN}$ & $0.72 \%$ & Shaw et al, forthcoming \\
\hline Monthly transition rate from $\mathrm{UN}$ to $\mathrm{NCN}$ & $1.19 \%$ & Workstream A analysis, ELSA 2002-04 \\
\hline $\begin{array}{l}\text { Fraction of people in UN who are eligible for } \\
\text { Blankshire care }\end{array}$ & $10 \%$ & Forder (2007) PSSRU Discussion Paper 2505 \\
\hline $\begin{array}{l}\text { Fraction of the above who actually receive } \\
\text { Blankshire care ONLY }\end{array}$ & $5 \%$ & Ribbe et al (1997), Age and Ageing 26 \\
\hline $\begin{array}{l}\text { Average time spent in state UN before transit- } \\
\text { ing to CF (in months) }\end{array}$ & 1.75 & $\begin{array}{l}\text { Modelling assumption to calibrate model to } \\
2004 \text { ELSA data: shorter time to CF due to } \\
\text { more critical need for this group }\end{array}$ \\
\hline $\begin{array}{l}\text { Average time spent in state UN before transit- } \\
\text { ing to CFO (in months) }\end{array}$ & 12 & Modelling assumption, as above \\
\hline $\begin{array}{l}\text { Average time spent in state UN before transit- } \\
\text { ing to CO (in months) }\end{array}$ & 10 & Modelling assumption, as above \\
\hline $\begin{array}{l}\text { Total number of people who age from } 64 \text { to } 65 \\
\text { each month }\end{array}$ & 1,320 & $\begin{array}{l}\text { ONS, Key Population and Vital Statistics, No. } \\
34,2007\end{array}$ \\
\hline Fraction of the above who age into NCN & $61 \%$ & Workstream A analysis, ELSA 2004 \\
\hline Fraction who age into UN & $11.6 \%$ & Workstream A analysis, ELSA 2004 \\
\hline Fraction who age into $\mathrm{CF}$ & $2.6 \%$ & Workstream A analysis, ELSA 2004 \\
\hline Fraction who age into CFO & $2.4 \%$ & Workstream A analysis, ELSA 2004 \\
\hline Fraction who age into $\mathrm{CO}$ & $21.4 \%$ & Workstream A analysis, ELSA 2004 \\
\hline
\end{tabular}


Brailsford, Evandrou, Luff, Viana, Vlachantoni and Willis

\begin{tabular}{|l|l|l|}
\hline Monthly death rate from NCN & $0.25 \%$ & Shaw et al (forthcoming) \\
\hline Monthly death rate from UN & $0.25 \%$ & Shaw et al (forthcoming) \\
\hline Monthly death rate from CF & $1.01 \%$ & NHS (2010) Deaths in Older Adults in England \\
\hline Monthly death rate from CFO & $1.01 \%$ & NHS (2010) Deaths in Older Adults in England \\
\hline Monthly death rate from CO & $1.39 \%$ & NHS (2010) Deaths in Older Adults in England \\
\hline Monthly death rate from CH & $7.01 \%$ & Tameside General Hospital (2006) \\
\hline Monthly transition rate from CF to NCN & $0.17 \%$ & Workstream A analysis, ELSA 2002-04 \\
\hline Monthly transition rate from CFO to NCN & $1.54 \%$ & Workstream A analysis, ELSA 2002-04 \\
\hline Monthly transition rate from CF to NCN & $1.35 \%$ & Workstream A analysis, ELSA 2002-04 \\
\hline Monthly hospital admission rate from all states & $8.7 \%$ & HES data 2007/08 \\
\hline Average length of hospital stay (months) & 0.3 & HES data 2007/08 \\
\hline Willingness and resources (WR) & 0 to 1 & User-input parameter for experimentation \\
\hline
\end{tabular}

\section{REFERENCES}

Brailsford, S.C., M.S. Desai and J. Viana. 2010. Towards the holy grail: combining system dynamics and discrete-event simulation in healthcare. Proceedings of the 2010 Winter Simulation Conference, Baltimore, Md, USA. B. Johansson, S. Jain, J. Montoya-Torres, J. Hugan, and E. Yücesan, eds

Brailsford S.C., Harper P.R., Patel B and Pitt M. 2009.. An Analysis of the Academic Literature on Simulation and Modelling in Healthcare. The Journal of Simulation; 3:130-140.

Brailsford, S.C. 2008. System Dynamics: What's in it for Healthcare Simulation Modelers. Proceedings of the 2008 Winter Simulation Conference, Miami, Fl, USA, Eds. S. J. Mason, R. Hill, L. Moench, and O. Rose. pp 1478-83..

Campbell, H., J. Karnon and R. Dowie. 2001. Cost analysis of a Hospital-at-Home initiative using discrete event simulation. Journal of Health Services \& Research Policy, 6:14-22

Desai, M.S., Penn, M.L., Brailsford S.C. and Chipulu M. 2008. Modelling of Hampshire Adult Servicesgearing up for future demands. Health Care Management Science 11: 167-176

Forder, J. (2007) Self-funded social care for older people: an analysis of eligibility, variations and future projections. PSSRU Discussion Paper 2505.

Glasby, J. 2012. Understanding Health and Social Care. 2nd ed. Bristol: The Policy Press.

Hill, M. Ed. 2000. Local Authority Social Services: An Introduction. Oxford: Blackwell.

House of Commons (1999) A Century of Change: Trends in UK statistics since 1900. London: UK Parliament. http://www.parliament.uk/documents/commons/lib/research/rp99/rp99-111.pdf, accessed 28.04.12.

Iles, N. J., and K. Lowton. 2008. "Young people with cystic fibrosis' concerns for their future: when and how should concerns be addressed, and by whom?" Journal of Interprofessional Care 22(4):436-438.

Katsaliaki, K., S.C. Brailsford, D. Browning and P. Knight. 2005. Mapping and planning of care pathways: a case study of intermediate care versus long term care solutions. Journal of Health Organisation and Management, 19: 57-72.

Katz, S. 1983. Assessing self-maintenance: Activities of daily living, mobility, and instrumental activities of daily living. Journal of the American Geriatrics Society, 31:721-727.

MASHnet, the UK Network for Modelling and Simulation in Healthcare. 2012. MASHnet website, www.mashnet.info, accessed 28.05.12

NHS (2010) Deaths in Older Adults in England. National End of Life Care Intelligence Network.

Office for National Statistics (ONS) (2004). Healthy Life Expectancy for Great Britain and England: Annual Estimates for 1981 to 2001. National Statistics Website Release, 22 July 2004.

ONS (2011a) National Population Projections 2010 based. London: ONS. 
ONS (2011b) Health expectancies at birth and at age 65 in the United Kingdom, 2007-9. Statistical bulletin 31 August 2011. Newport: ONS.

ONS (2012) Historic and Projected Mortality Data (1951 to 2060) from the UK Life Tables, 2010-base published 26 March 2012. http://www.ons.gov.uk/ons/rel/lifetables/historic-and-projected-mortalitydata-from-the-uk-life-tables/2010-based/index.html, accessed 28.05.12.

Ribbe, M.W. et al (1997) Nursing homes in 10 nations: a comparison between countries and settings. Age and Ageing 26 (2): 3-12.

Shaw, R., Vlachantoni, A., Evandrou, M. and Falkingham, J. (forthcoming) The disablement process in later life: evidence from the English Longitudinal Study of Ageing.

Sillett, J., A. Cookson, and C. Elliott. 2008. Never Too Late For Living: Inquiry into Services for Older People. London: All Party Parliamentary Local Government Group and Local Government Information Unit.

Vlachantoni, A., Shaw, R., Willis, R., Evandrou, M., Falkingham, J. and Luff, R. (2011) Measuring unmet need for social care amongst older people. Population Trends 145.

Tameside General Hospital (2006) Standardised Mortality Rates at Tameside General Hospital

Whole Systems Partnership, 2012. www.thewholesystem.co.uk, accessed 28.04.12.

Wolstenholme, E.F. 1993. A case study in community care using systems thinking. Journal of the Operational Research Society, 44: 925-34.

\section{AUTHOR BIOGRAPHIES}

SALLY C. BRAILSFORD is Professor of Management Science at the University of Southampton, UK. She received a BSc in Mathematics from the University of London, and MSc and PhD in Operational Research from the University of Southampton. Her research interests include simulation modeling methodologies, system dynamics, health service research and disease modeling, and the modeling of human behavior in healthcare systems. She is chair of the European Working Group on OR Applied to Health Services (ORAHS) and is an Editor-in-Chief of Health Systems. She is on the editorial boards of Health Care Management Science, the Journal of Simulation and the Flexible Services \& Manufacturing Journal. Her email address is s.c.brailsford@soton.ac.uk.

MARIA EVANDROU is Professor of Gerontology and Director of the Centre for Research on Ageing at the University of Southampton, as well as Co-Director of the ESRC Centre for Population Change. Her research interests span three distinct but related areas of investigation: inequalities in later life; informal carers and employment; and the retirement prospects of future generations of elders. Her email address is maria.evandrou@soton.ac.uk.

REBEKAH LUFF is a Lecturer in Social Science Research Methods in the Faculty of Social and Human Sciences at the University of Southampton. She received a BSc in Psychology from Dundee University, an MSc in Research Methods in Psychology and a PhD in joint Psychology and Sociology from the University of Surrey. Her research interests include the long term care of older people, particularly in care homes and the emotion work of care staff. Her email address is r.luff@soton.ac.uk.

JOE VIANA is a Research Fellow on the Care Life Cycle project at the University of Southampton. He received a BSc with Honors in Sport and Health Science with Psychology from the University of Southampton, and MSc and $\mathrm{PhD}$ in Management Sciences from the University of Southampton. His email address isJ.Viana@soton.ac.uk. 
ATHINA VLACHANTONI is a Lecturer in Gerontology at the Centre for Research on Ageing at the University of Southampton. She holds MSc and PhD degrees in social policy from Oxford University and the London School of Economics. Her research interests combine the broad areas of aging and social policy, focusing on the implications of population aging for social care provision and the impact of informal care provision on employment patterns and pension rights. Her recent publications include the book "Women, politics and pensions" (Lambert Academic Publishing, 2009) and the journal article "The demographic and socio-economic characteristics of older carers: evidence from the ELSA" (Population Trends, 2010). Her email address is a.vlachantoni@soton.ac.uk.

ROSALIND M. WILLIS is a Lecturer in Gerontology and SSCR Fellow at the Centre for Research on Ageing at the University of Southampton. She received a BSc in Psychology from Bangor University, an MSc in Forensic Psychology from the University of Kent, and a PhD in Gerontology from King's College London. Her research interests include the influence of ethnicity and culture on informal care, and on the use of health and social care services in later life. Her email address is r.m.willis@soton.ac.uk. 